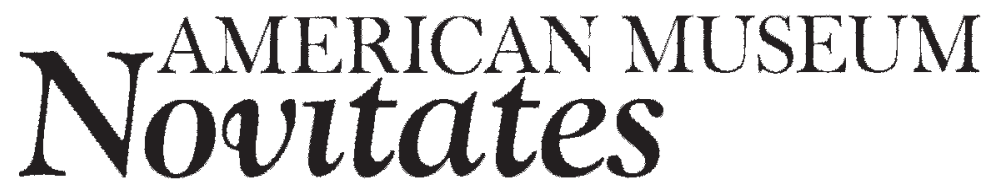

PUBLISHED BY THE AMERICAN MUSEUM OF NATURAL HISTORY CENTRAL PARK WEST AT 79TH STREET, NEW YORK, NY 10024 Number 3586, 11 pp., 4 figures, 2 tables

September 6, 2007

\title{
Phylogenetic Analysis of the Neotropical Pseudopolybia de Saussure, 1863, with Description of the Male Genitalia of Pseudopolybia vespiceps (Hymenoptera: Vespidae, Epiponini)
}

\author{
SERGIO R. ANDENA, ${ }^{1}$ FERNANDO B. NOLL, ${ }^{2}$ JAMES M. CARPENTER, ${ }^{3}$ AND \\ RONALDO ZUCCHI ${ }^{1}$
}

\begin{abstract}
The male genitalia of Pseudopolybia vespiceps are described and compared to congeners. Characters of the male genitalia are combined with morphological characters of the females and nests and used in a phylogenetic analysis. The single cladogram resulting supports monophyly of the genus Pseudopolybia and interrelationships among the species as: $P$. langi $+(P$. difficilis + $(P$. compressa $+P$. vespiceps $))$. A new, illustrated identification key is presented.
\end{abstract}

\section{INTRODUCTION}

Pseudopolybia is a genus of neotropical swarm-founding wasps (Tribe Epiponini), distinguished by the third segment of the labial palpi bearing a short, stout, curved bristle near its apex, and the number of palpal segments being six maxillary and four labial (Richards, 1978). The genus comprises four species, which range from Nicaragua to southern Brazil, and they are found mainly in rainforest (Hanson and Gauld, 1995; Richards and Richards, 1951; Richards, 1978). Although there are few species, they present several taxonomic problems, because both $P$. compressa and $P$. vespiceps occur in striking color forms that "in some respects look like species, though they show no structural differences" (Richards, 1978: 224). In the most recent revision, Richards (1978)

\footnotetext{
${ }^{1}$ FFCLRP-USP. Av. Bandeirantes, 3900, Ribeirão Preto-SP, CEP 14040-901, Brazil (sandena@usp.br).

${ }^{2}$ Departamento de Zoologia e Botânica, Instituto de Biociências, Letras e Ciências Exatas, UNESP, Rua Cristóvão Colombo, 2265; 15054-000, São José do Rio Preto, SP, Brazil (noll@ibilce.unesp.br).

${ }^{3}$ Curator, Division of Invertebrate Zoology, American Museum of Natural History (carpente@amnh.org).
} 
treated these color variants as "morphs": $P$. compressa comprised the morphs compressa, luctuosa and laticincta, and Pseudopolybia vespiceps comprised the morphs vespiceps and testacea. These names had been first described as distinct species or varieties; they were later reduced to varieties of the respective species (Bequaert, 1938) and are now synonyms, as the term "morph" is without taxonomic standing.

Nests of three of the species of Pseudopolybia have been described (Wenzel, 1998): $P$. compressa, $P$. difficilis and $P$. vespiceps. They are usually arboreal, with the pedicel fibrous and cell marginal and lower combs hanging from the upper ones, normally by a single more or less central petiole (Richards, 1978). The spherical or tapering envelope is not in contact with the combs, and is laminar or imbricate, with downwardly opening pockets built on the outside of the envelope. The entrance hole is a simple hole at the lowest point of the envelope. A nest of $P$. langi from French Guiana is mentioned in the literature (Dejean et al., 1998), and the specimen is now in the collection of the American Museum of Natural History $(\mathrm{AMNH})$. It is an incipient nest, arboreal, a single comb lacking an envelope and attached by a pedicel to the substrate (a leaf). A more complete specimen was obtained in Amapá, Brazil, by Orlando Tobias Silveira, who kindly sent us a photograph. Although the specimen is damaged, essential aspects of its architecture are visible: the nest consists of several combs attached to the substrate (a leaf), evidently with some degree of stacking present; there is an envelope that is not in contact with the combs and that consists of a simple sheet, without pockets and without a spoutlike entrance. In the absence of the imbrications in the envelope, $P$. langi is primitive relative to the other species in the genus, a conclusion that is true for other characters, as will be seen.

Carpenter and Mateus (2004) presented the first detailed descriptions of male genitalia of Pseudopolybia and related genera (see also Charnley, 1973). Probably due to intermittent male production in social wasps (Jeanne, 1991), few works on male genitalia have been published. This type of character seems to be important in phylogenetic investigation, an issue not well explored for the Polistinae (Carpenter, 1991; Wenzel and Carpenter, 1994). In this work, a phylogenetic analysis of Pseudopolybia using male genitalia and other characters is presented.

\section{MATERIALS AND METHODS}

Specimens were examined at the AMNH and at the Faculdade de Filosofia, Ciências e Letras de Ribeirão Preto da Universidade de São Paulo, and were obtained by loans from Museu Paraense Emilio Goeldi, Belém, Pará, Brazil (MPEG); Museu de Zoologia da Universidade de São Paulo, São Paulo, Brazil (MZSP); Universidade Federal do Paraná, Curitiba, Paraná, Brazil (UFPR); and Instituto de Investigación de Recursos Biológicos Alexander Von Humboldt, Bogotá, Colombia (IIRBAVH). Additional material was examined in the Hymenoptera Collection of the Instituto Nacional de Pesquisas da Amazônia, Manaus, Amazonas, Brazil (INPA). Localities of specimens are listed in appendix 1.

Specimens dissected and illustrated by Carpenter and Mateus (2004) were available in the present study. In addition, males of Agelaia cajennensis (from promenades St. Jeandu-Maroni, French Guiana), Parachartergus fraternus (from Valle Chanchamayo, San Ramon, Peru), and Pseudopolybia vespiceps (from São Paulo, Brazil) were relaxed and the genitalia extracted. The genital capsule was cleared in lactophenol and examined under glycerin. The genitalia of these taxa are illustrated in figure 4; the specimens are deposited in the AMNH. Figures of the genitalia of Apoica gelida and Angiopolybia pallens (both based on specimens from Arima Valley, Trinidad), given to Carpenter by the late $\mathbf{J}$. van der Vecht, were also examined. Finally, nest characters were taken from Wenzel (1998).

Measurements and illustrations were taken using a Leica MZ 7.5 stereomicroscope with drawing tube, Leica model DFC 280 digital camera, and Leica IM 50 software.

Twenty morphological characters of the females, six from male genitalia, and three nest characters for the species of Pseudopolybia were assembled in a data matrix 
TABLE 1

Character Matrix for Pseudopolybia

The following symbols are used: ? (not seen); - (inapplicable)

\begin{tabular}{|c|c|c|c|c|c|c|c|c|c|c|c|c|c|c|c|c|c|c|c|c|c|c|c|c|c|c|c|}
\hline & & & 5 & 5 & & & & & & & & & & & & & & & & & & & & & & & \\
\hline & & 0 & $\begin{array}{lll}0 & 1\end{array}$ & & 0 & 0 & 0 & 0 & 3 & 0 & O & 0 & 0 & 0 & 0 & 0 & 1 & 0 & 0 & 1 & 0 & 0 & . & 0 & 0 & & \\
\hline 5 & 0 & 00 & $\begin{array}{lll}0 & 1\end{array}$ & 10,1 & 10 & 0 & 1 & 0 & & 0 & 0 & 0 & 0 & 0 & ) & 0 & 1 & 1 & 0 & 1 & 0 & 0 & 1 & 0 & 0 & 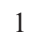 & \\
\hline & 0 & 00 & $\begin{array}{lll}0 & 1\end{array}$ & 10 & 0 & 0 & 0 & 0 & & 0 & & 0 & 1 & 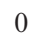 & & 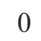 & 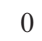 & . & & 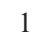 & 0 & 1 & 0 & 0 & 1 & & 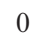 \\
\hline & 1 & 00 & 11 & 0 & 0 & 0 & 0 & 1 & 2 & 0 & c & 0 & 0 & 0 & 1 & 0 & . & 0 & & 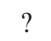 & $?$ & & 9 & $?$ & 1 & 1 & 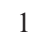 \\
\hline & 1 & 00 & $\begin{array}{ll}0 & 0\end{array}$ & & 11 & 1 & 1 & 1 & 1 & 1 & 0 & 0 & 0 & 1 & . & 1 & 1 & & & 0 & 0 & ) & & 1 & 2 & 1 & \\
\hline & 1 & 00 & $\begin{array}{lll}0 & 1\end{array}$ & & 0 & 1 & 0 & 1 & 1 & 1 & 0 & 0,1 & 0 & 1 & & 1 & 0 & 0 & 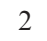 & 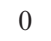 & 0 & 0 & 1 & 1 & 2 & 1 & 1 \\
\hline & 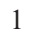 & 00 & 00 & 0 & 0 & 1 & 0 & 1 & 1 & 1 & 0 & 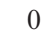 & 0 & 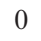 & . & 0 & 0 & 0 & 2 & 0 & 0 & ) & 0 & 1 & 2 & 1 & 1 \\
\hline & 1 & $\begin{array}{ll}0 & 1\end{array}$ & $\begin{array}{lll}0 & 1\end{array}$ & & 0 & 0 & 0 & 0 & 0 & 0 & & 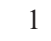 & 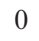 & - & & 1 & 1 & 0 & 1 & 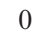 & 0 & L & 0 & 1 & 1 & 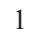 & 0 \\
\hline Leipomeles $d$ & 1 & 11 & 00 & 0 & 0 & & 0 & 0 & 2 & 0 & 0 & 1 & 0 & 0 & 0 & 0 & 0 & 0 & 0 & 1 & 1 & 1 & 0 & 1 & 1 & 1 & 0 \\
\hline \multicolumn{28}{|l|}{ Nectarinella } \\
\hline & & 11 & 10 & & 10 & 0 & 0 & 1 & 0 & 0 & & & 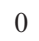 & 2 & & 1 & 0 & & & 1 & 0 & & 1 & 1 & 1 & & \\
\hline hartergellus punctatior & 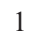 & 11 & 11 & & 10 & 0 & & 1 & 0 & 0 & r & 1 & 0 & 1 & 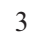 & 1 & 0 & 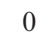 & 0 & 0 & 0 & 0 & 1 & 1 & 1 & 1 & \\
\hline
\end{tabular}

for phylogenetic reconstruction (table 1). Analysis of the data matrix was undertaken with the program NONA (Goloboff, 1999a), using WINCLADA as the interface (Nixon, 1999); the resulting cladogram is shown in fig. 1. Multistate character was treated as nonadditive except for characters 16 and 27, in which nested similarity was observed. Characters were polarized by rooting with outgroups (Nixon and Carpenter, 1993), represented herein by species of the distantly related genera Apoica, Agelaia, and Angiopolybia, as well as Chartergellus, Leipomeles, Nectarinella, and Parachartergus, the other four genera of Epiponini that have the curved bristle on the labial palpi. Characters and states are listed in table 2, and illustrated in figures 2-4.

\section{RESULTS AND DISCUSSION}

Figures of the male genitalia of $P$. compres$s a$ and $P$. difficilis were presented by Carpenter and Mateus (2004: figs. 8-9). The male genitalia of $P$. vespiceps are illustrated in figure 4. Richards (1978) described males of $P$. vespiceps as being similar to females but yellower: head mostly yellow except the upper part of frons, antennae black above, scape yellow beneath, flagellum brownish beneath, the mesosoma with many small yellow marks, the metasoma browner. The clypeus also has silvery hairs, and the gena is narrow. (Typically, most epiponine males, including Pseudopolybia, have the gena relatively nar- row and the clypeus with silvery hairs; they also have an extra antennal article and the extra, seventh metasomal sternum flattened.) We noted some specimens of $P$. vespiceps that have the antenna completely yellow or brownish, which may reflect regional variation. Male genitalia of $P$. vespiceps (fig. 4) have long and numerous hairs on the parameral spine; the basal angle of the paramere obtuse (fig. 4c3); the apical angle of the paramere broad (fig. 4b3); the ventral process of the aedeagus short and angular (fig. 4a3); the digitus apically broadly pointed; and the basal process of the digitus present. Apparently, this species has less numerous hairs on the paramere than other Pseudopolybia species (cf. fig. 4 with Carpenter and Mateus: figs. 8-9), while the pointed digitus places this species closer to $P$. compressa, which also has this feature, than to $P$. difficilis (see the discussion below).

Analysis of the matrix, using implicit enumeration, resulted in a single cladogram (fig. 1), of length 56, consistency index 0.64, and retention index 0.70 . This tree is stable to both successive (using the rescaled consistency index) and implied weighting (default concavity in the program Piwe; Goloboff, 1999b). Pseudopolybia is supported as a monophyletic group, with relationships among the species showing $P$. langi as relatively basal, and $P$. difficilis as sister-group to a clade composed of $P$. vespiceps $+P$. compressa.

According to previous authors (Carpenter, 1991; Wenzel and Carpenter, 1994), the third 


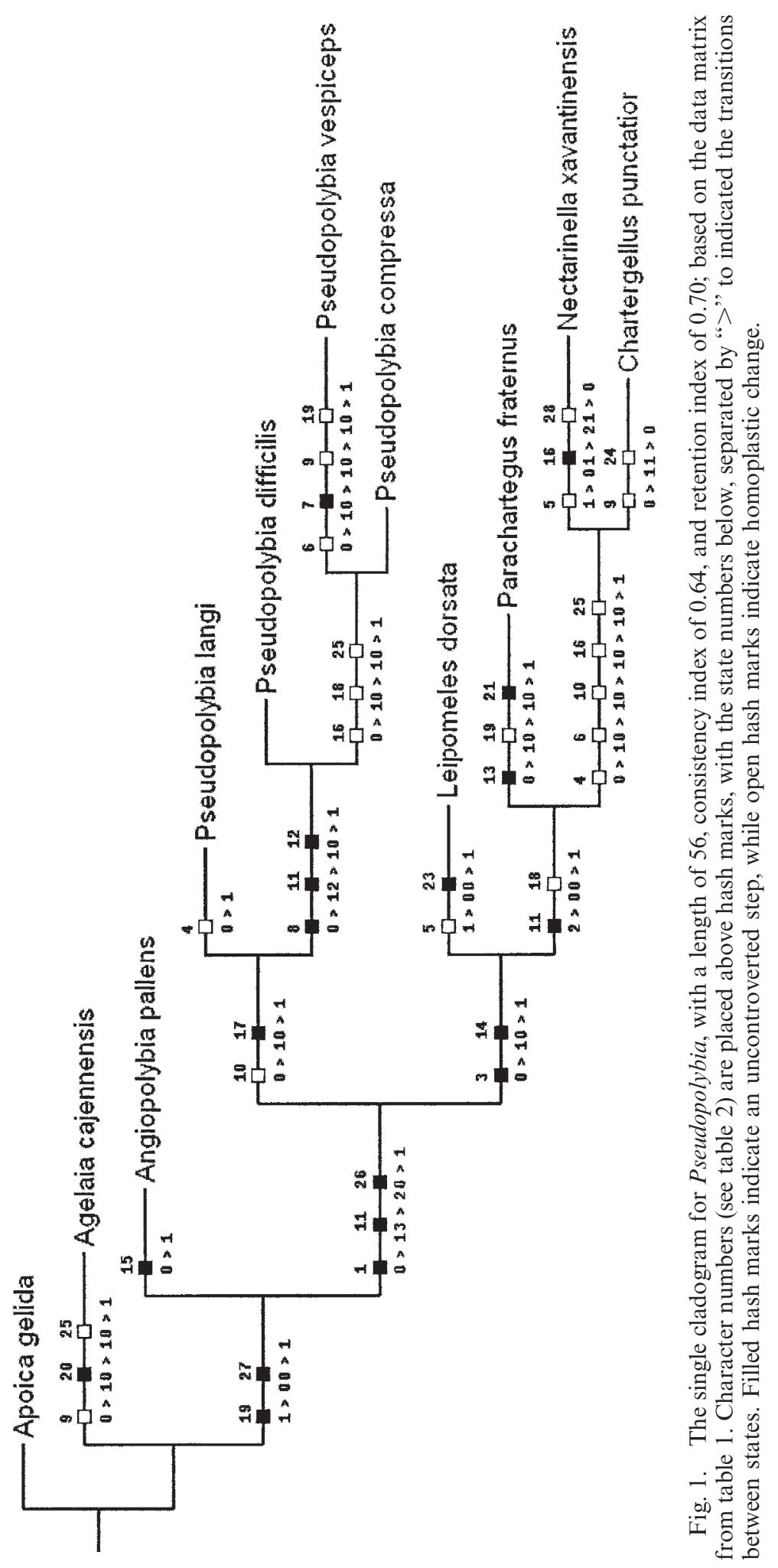


TABLE 2

\section{Character list for Pseudopolybia. Numerical scores for each state follow the "="}

1. Third labial palpomere: without curved bristle $=0$; with curved bristle $=1$.

2. Maxillary palpi: 6 segments $=0 ; 5$ segments $=1$.

3. Labial palpi: 4 segments $=0 ; 3$ segments $=1$.

4. Third antennal article: twice as long as fourth article $=0$; about 1,5 times as long as fourth article $=1$.

5. Eyes: bare $=0$; with bristles $=1$.

6. Clypeus: touching the eyes $=0$; not touching the eyes $=1$.

7. Clypeal apex: sharply pointed $=0$ (fig. $2 \mathrm{~A} 1$ ); feebly pointed $=1$ (fig. $2 \mathrm{~A} 2$ ).

8. Gena: at bottom of eyes, narrower than eyes $=0$; at bottom of eyes, angled, wider than eyes $=1$.

9. Malar space: shorter than or equal to 4 th antennal article $=0$ (fig. $2 \mathrm{~B} 1$ ); longer than 4 th antennal article $=1$ (fig. 2B2).

10. Occipital carina: present $=0$; absent $=1$.

11. Dorsal pronotal carina: ending close to posterior margin of pronotum $=0$; ending close to midpoint of pronotum $=1$ (fig. 2C1); weak, evanescent $=2$ (fig. 2C2); trace, absent $=3$.

12. Pronotal fovea: in a shallow concavity $=0$; in a deep concavity $=1$.

13. Scrobal sulcus: present $=0$; absent $=1$.

14. Dorsal groove: present $=0$; absent $=1$.

15. Scutellum: with impressed line $=0$; without impressed line $=1$.

16. Metanotum: long, curved $=0$; short, compressed $=1$ (fig. $2 \mathrm{D} 1,2 \mathrm{D} 2$ ); vertical $=2$.

17. Propodeal concavity: narrow $=0$; broad, shallow $=1$; broad, deep $=2$; propodeum nearly flat $=3$.

18. First metasomal segment: longer than wide $=0$ (fig. $3 \mathrm{~A} 1$ ); wider than long $=1$ (fig. $3 \mathrm{~A} 2$ ).

19. Prestigma: as long as wide $=0$; longer than wide $=1$.

20. Tip of prestigma: truncate $=0$; rounded $=1$.

21. Paramere hairs: absent $=0$; present, short hairs $=1$; present, long hairs $=2$.

22. Paramere basal angle: obtuse (fig. $4 \mathrm{c} 2,4 \mathrm{c} 3)=0$; acute $=1$ (fig. $4 \mathrm{c} 1$ ).

23. Paramere apical angle: broad (fig $4 \mathrm{~b} 1,4 \mathrm{~b} 2,4 \mathrm{~b} 3)=0$; narrow $=1$.

24. Ventral process of aedeagus: short, angular $=0$ (fig . 4a1, 4a3); narrow, reduced $=1$ (fig. 4a2).

25. Digitus shape: rounded $=0$; pointed $=1$.

26. Basal process of digitus: absent $=0$; present $=1$.

27. Nest envelope: absent $=0$; present, single sheet $=1$; present, laminar to imbricate $=2$.

28. $\quad$ Nest pedicels: absent $=0$; present $=1$.

29. Nest entrance: downward spout $=0$; simple hole $=1$.

labial palpomere with a curved bristle (character 1, state 1; see character list) is apomorphic for the clade Pseudopolybia + (Leipomeles + (Parachartergus + (Nectarinella + Chartergellus))), and that is also our result (fig. 1). ${ }^{4}$ The loss of the occipital carina (character 10, state 1) is a derived character found in Nectarinella, Chartergellus and all Pseudopolybia species, with two independent origins (fig. 1). In previous analyses, this feature was the only synapomorphy for

\footnotetext{
${ }^{4}$ Note that the relationships of these five genera differ from the topology in Wenzel and Carpenter (1994), which shows Pseudopolybia + (Parachartergus + (Leipomeles + $($ Chartergellus + Nectarinella $))$ ). In either case, Pseudopolybia in is the most basal genus, and both because that is the focus of this study, and due to the small number of species sampled in our outgroup, we will defer discussion.
}

Pseudopolybia. Here, a broad, shallow propodeal concavity (character 17, state 1) is an additional synapomorphy for Pseudopolybia. Several other morphological characters are potentially synapomorphies, but because $P$. langi is unknown for male genitalia, the optimizations are ambiguous on figure 1 . One feature of nest architecture, nest entrance a simple hole (character 29, state 1), is optimized as a synapomorphy for Pseudopolybia.

Richards (1978) placed Chartergellus, Leipomeles, Parachartergus and Pseudopolybia in a group with long hairs on the paramere spine (character 21, state 2 , in the character list), but, as pointed out by Carpenter and Mateus (2004), this is a characteristic exclusive to Pseudopolybia. In fact, Parachartergus fraternus (fig. 4), $P$. apicalis and $P$. griseus (see Carpenter and Mateus, 2004: figs. 6-7) 

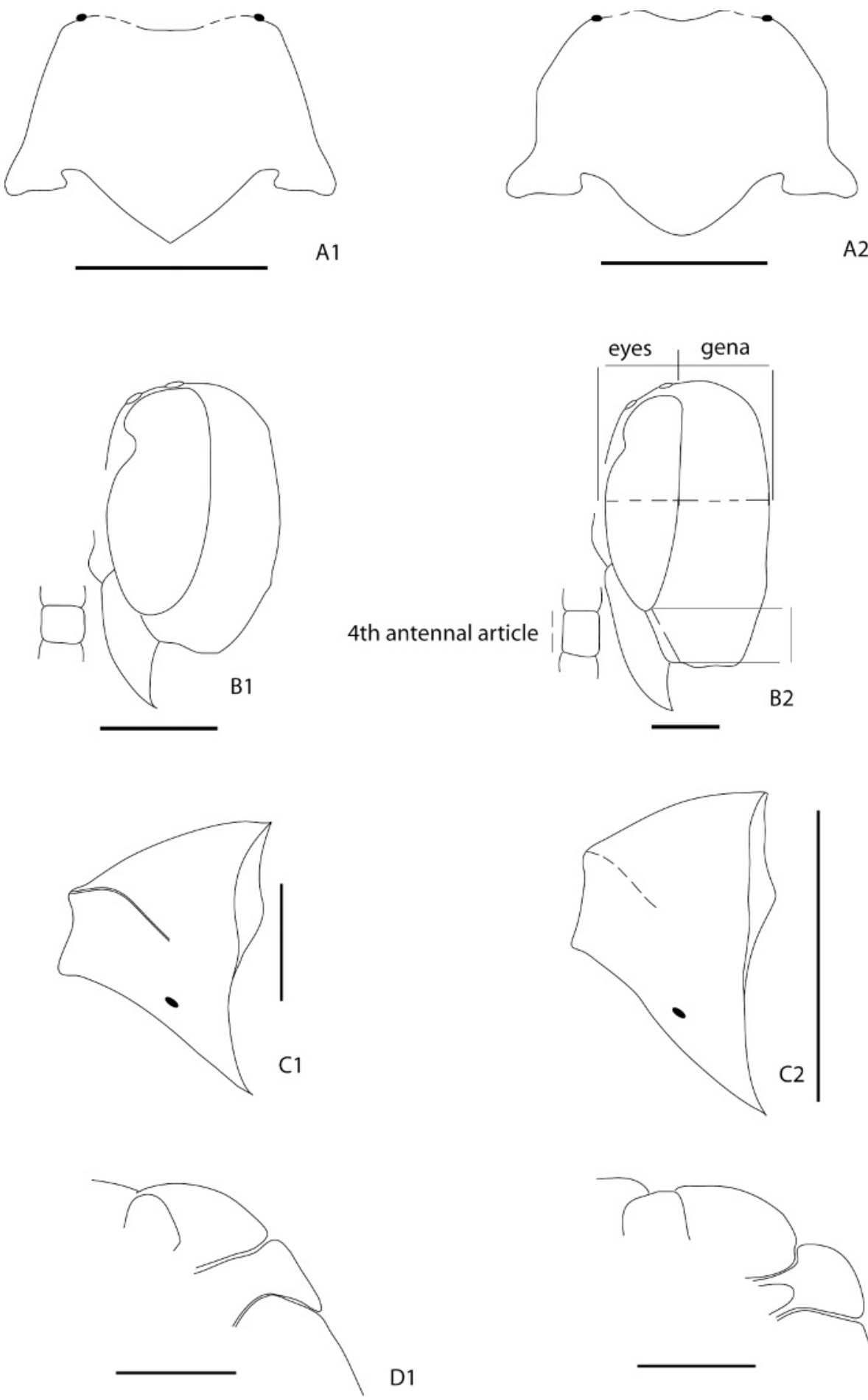

D1

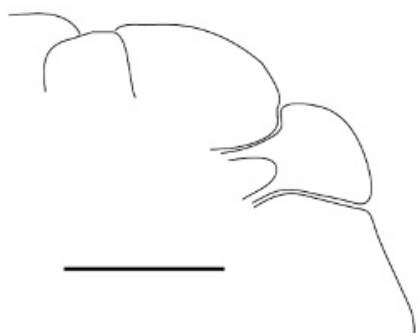

D2

Fig. 2. Characters of Pseudopolybia. A, clypeus in frontal view. A1, P. compressa; A2, P. vespiceps. B, head in lateral view. B1, P. compressa; B2, P. vespiceps. C, pronotum in lateral view. C1, P. compressa; $\mathrm{C} 2$, $P$. langi. D, metanotum in lateral view. D1, P. compressa; D2, P. vespiceps. Scale bars $=1.0 \mathrm{~mm}$. 


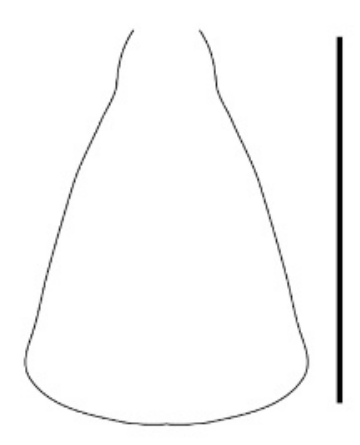

A1
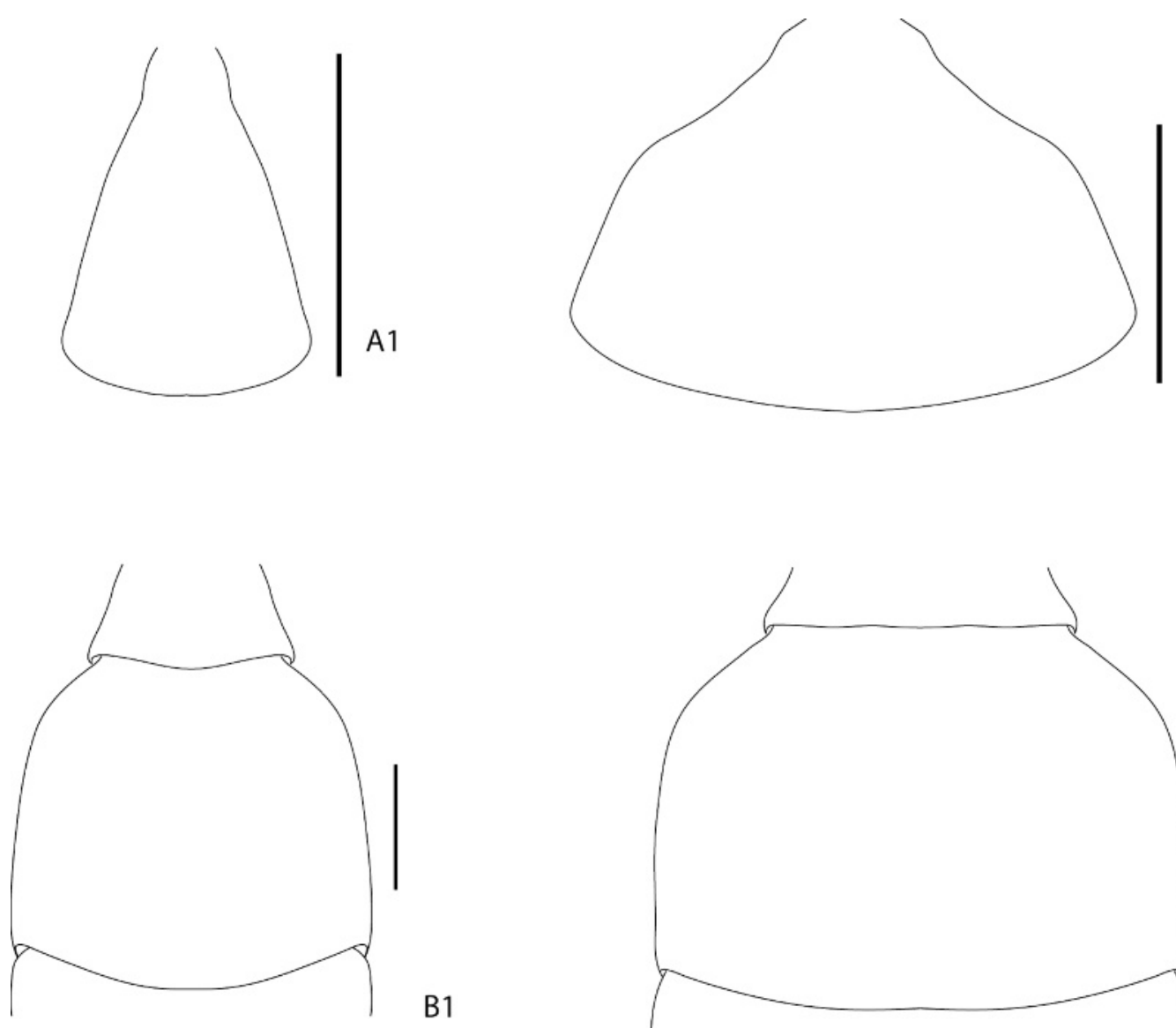

B1

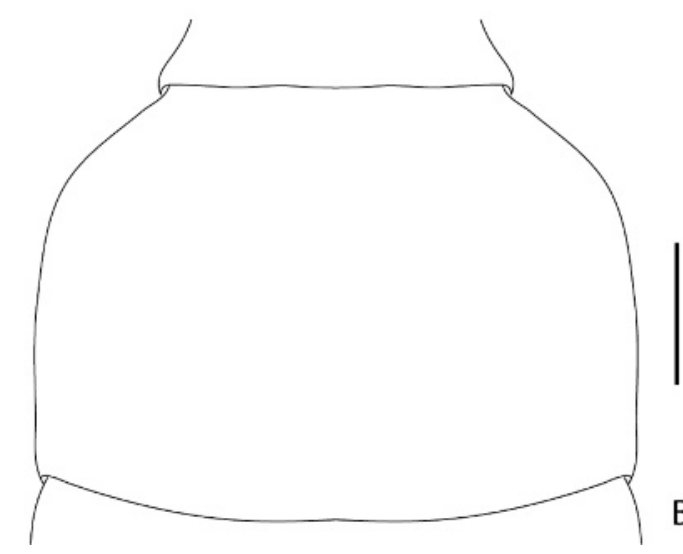

Fig. 3. Characters of Pseudopolybia. A, first metasomal segment in dorsal view. A1, P. langi; A2, P. vespiceps. B, second metasomal segment in dorsal view. B1, P. difficilis; B2, P. vespiceps. Scale bars $=$ $1.0 \mathrm{~mm}$.

have hairs, but they are shorter and less numerous than in Pseudopolybia, as Carpenter and Mateus (2004) also pointed out. Pseudopolybia vespiceps is less hairy than $P$. difficilis and $P$. compressa but clearly shows long hairs (fig. 4). Because of the fact that the male genitalia of $P$. langi have not been described, it is not clear whether the state "long and numerous hairs" is synapomorphic for Pseudopolybia as a whole, or just for the clade $P$. difficilis $+(P$. vespiceps $+P$. compres$s a)$. The state "short hairs" is possibly synapomorphic for Parachartergus (fig. 1). All other taxa considered here have no hairs on the parameral spine. Carpenter and Mateus (2004: 298) considered the state of hairs on the parameral spine as of uncertain polarity, stating, "Study of additional genera besides those considered here is required to settle this." In our results (fig. 1), which includes three other genera than those studied by Carpenter and Mateus (2004), the primitive state is "hairs absent", and this may be general for Epiponini. Hence, the loss of hairs cannot support the grouping of genera besides Pseudopolybia which have lost the fourth labial palpomere (character 2, state 1), as suggested by Carpenter and Mateus (2004). We conclude that the different types of "hairs on the parameral spine" had independent origins in Pseudopolybia and Parachartergus.

According to Carpenter and Mateus (2004), a very narrow, reduced, almost hooking shape 

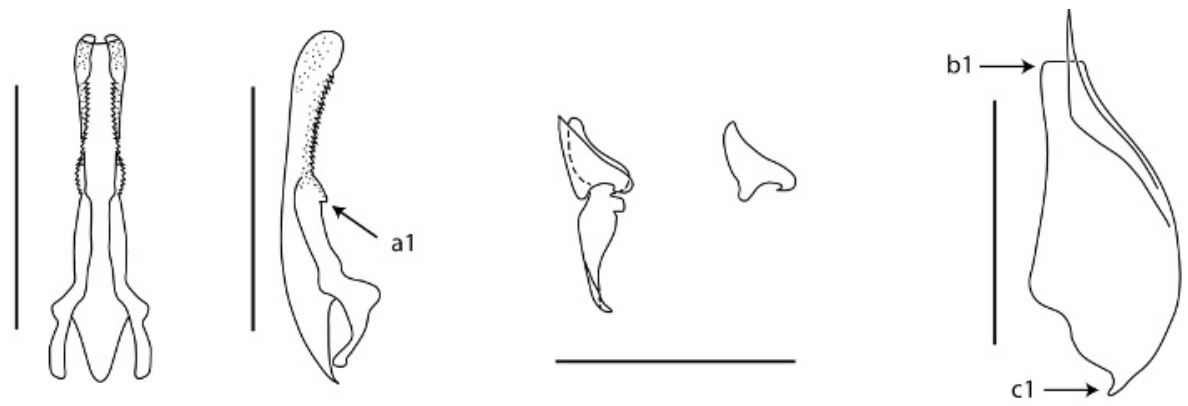

Agelaia cajennensis
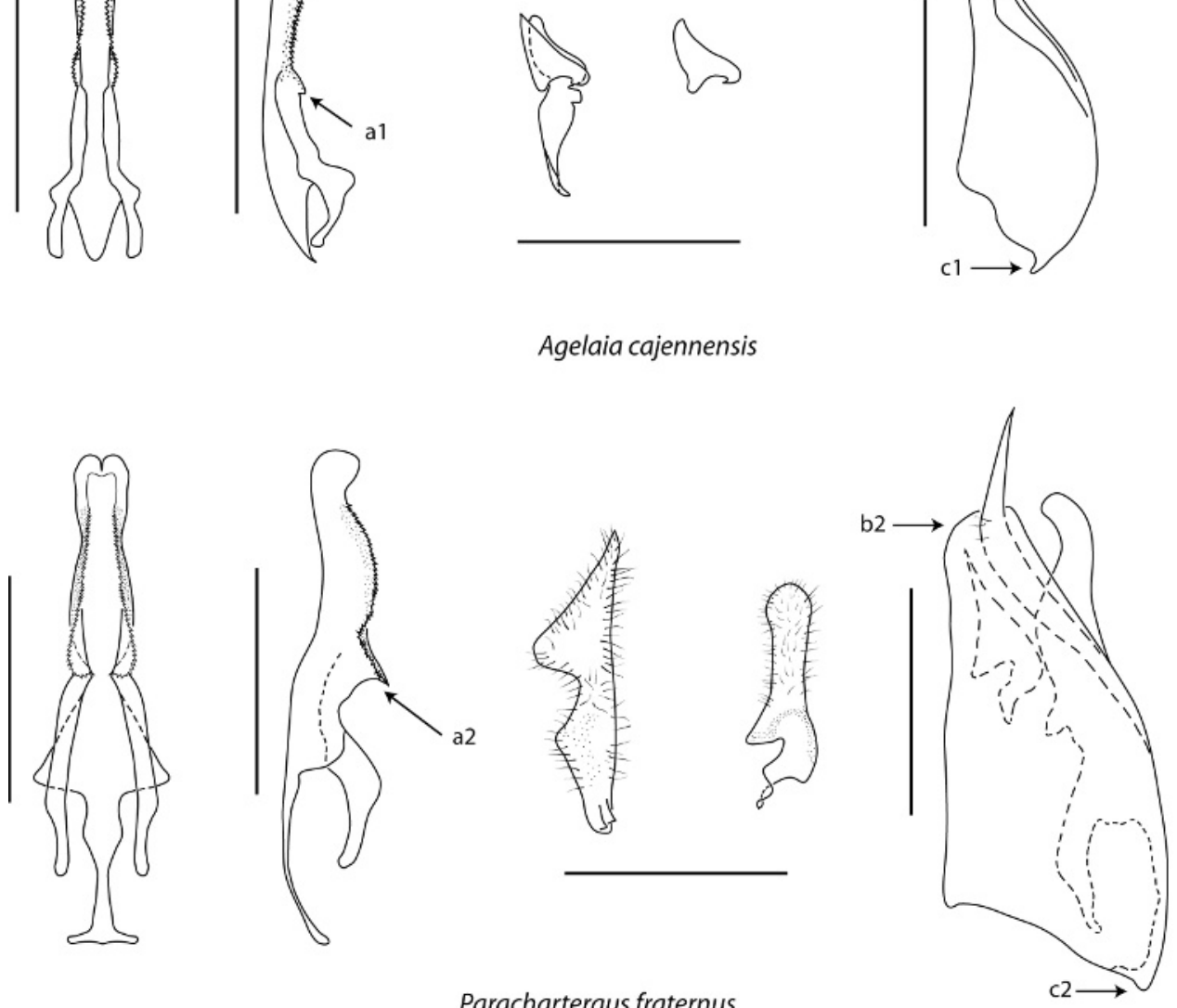

Parachartergus fraternus
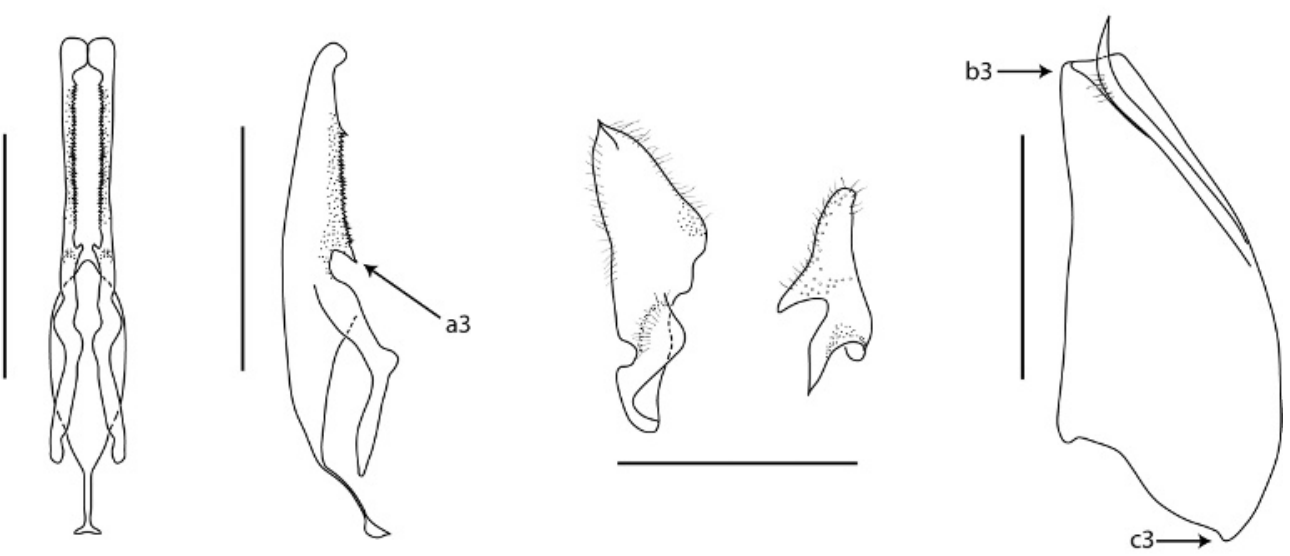

Pseudopolybia vespiceps

Fig. 4. Male genitalia: from left to right side = aedeagus in ventral view; aedeagus in lateral view; cuspis; digitus and paramere in lateral view. Scale bars $=1.0 \mathrm{~mm}$. 
of the ventral process of the aedeagus (character 24 , state 1 , in the character list; fig. 4a2) in most of these genera contrasts with the short angular process (character 24, state 0; fig. 4av) in Pseudopolybia, but this is also found in Chartergellus. If the narrow reduced shape is apomorphic, then Chartergellus either shows a reversal or is misplaced (Carpenter and Mateus, 2004). Because $P$. langi was not observed, the shape of the ventral process of aedeagus is ambiguous on our cladogram, but the apomorphic condition (narrow, reduced) is found in Angiopolybia, Leipomeles, Parachartergus and Nectarinella. Regardless of whether we assume that $P$. langi has the ventral process of aedeagus short, angular, as in other species of Pseudopolybia and Chartergellus, the character optimizes as two independent acquisitions of the state short, angular.

The shape of the digitus (character 25 in the character list) is variable in Pseudopolybia. Pseudopolybia compressa and $P$. vespiceps have the digitus pointed apically; it is also pointed in Nectarinella and Chartergellus. It is rounded in the remaining taxa. As stated by Carpenter and Mateus (2004), this is not a readily interpretable pattern. In our analysis, this character is homoplastic but supports the clade of $P$. compressa $+P$. vespiceps, with an independent origin in Nectarinella + Chartergellus.

The basal angle of the paramere acute (character 22, state 1 , in the character list; fig. 4c1) seems to be plesiomorphic, as the most basal genera have this state (Apoica, Agelaia and Angiopolybia), with a reversal in Nectarinella and Leipomeles. The optimization of this character is ambiguous on the cladogram of figure 1 , and because $P$. lang $i$ has not been observed for the male genitalia, it is not clear whether a reversal to basal angle of the paramere obtuse could be apomorphic for Pseudopolybia.

Carpenter and Mateus (2004) mentioned that the apical angle of the paramere (character 23 in the character list) is homoplastic at the generic level, because Leipomeles, Parachartergus griseus, and, to some extent, $P$. apicalis and Marimbonda (= Leipomeles) have a narrow apical angle. Inasmuch as $P$. fraternus (fig. 4b2) possesses a broad apical angle of the paramere, as in the other species studied here, this character is homoplastic within the genus Parachartergus.

We did not observe a small sclerite basad of aedeagus in Pseudopolybia vespiceps, as in congeners studied by Carpenter and Mateus (2004: figs. 8-9). The dissections on which those figures are based are not extant, but when we dissected an additional $P$. compressa, we did not observe such a sclerite as depicted in Carpenter and Mateus (2004: fig. 8). We are unable to say what the structure might be and must, for the present, consider it dubious. We have therefore omitted it from the matrix.

Pseudopolybia langi seems correctly placed as the most basal species of Pseudopolybia (see fig. 1), because this species retains several symplesiomorphies shared with the outgroups. The pronotal fovea is in a shallow concavity in $P$. langi, whereas it is in a deep concavity in other species of Pseudopolybia; the gena is relatively narrow below (wide in the other species); and the weak pronotal carina leads to optimization of the short pronotal carina of the other species as a synapomorphy, because the state found in the basal species of Epiponini analyzed here is absence of the carina. The nest envelope lacks the imbrications found in the other species of Pseudopolybia, which is clearly a primitive condition.

Pseudopolybia difficilis differs from $P$. compressa and $P$. vespiceps in three characters, all of them homoplastic, which unite the latter two as a clade. These are the metanotum (long, curved versus compressed), first metasomal segment (longer than wide versus wider than long) and digitus shape (rounded versus pointed). The derived condition in each character is convergently acquired in $P$. compressa $+P$. vespiceps. These two species are certainly very similar, and their placement in the same clade is reasonable, but there are several diagnostic characters that can separate the species, as indicated in the key.

The data on male genitalia published by Carpenter and Mateus (2004) and the new data described here proved phylogenetically informative and, together with other morphological characters, helped in elucidating the relationships of the species of Pseudopolybia. We hope that this study stimulates other such analyses within Epiponini. 


\section{IDENTIFICATION KEY TO SPECIES OF THE GENUS PSEUDOPOL YBIA}

An identification key to Pseudopolybia species is provided below, excluding the "morphs" of Richards (1978), which we conclude do not merit any treatment other than as synonyms. Ducke (1910) had reported that the forms of $P$. compressa can be found on the same nest, and while Richards (1978) stated that he felt this needed more verification, a colony collected by James M. Carpenter (from Napo Province, Ecuador, $8 \mathrm{~km}$ west of Misahualí) contained both laticincta and luctuosa. Figures 2 and 3 show some characters to aid in species recognition.

1 Dorsal pronotal carina very weak (fig. 2C2); first metasomal segment much longer than wide (fig. 3A1); eyes densely haired; small species $(6-8 \mathrm{~mm})$; yellow with three brown stripes on the scutum; metasoma brownish

.............. P. langi Bequaert

1' Dorsal pronotal carina lamellate laterally (fig. 2C1); first metasomal tergum nearly as broad (fig. 3A1) as or much broader than long (fig. 3A2); eyes with or without hairs; larger species $(13-15 \mathrm{~mm})$; yellow to black ................ 2

2 First and second metasomal segment a little longer than wide (figs. 3A1 and 3B1); metanotum not compressed; yellow with black marks on the head and mesosoma; three black stripes on the scutum; metasoma brownish. . . . . . . . P. difficilis (Ducke)

2' First and second metasomal segment about twice as wide as long (figs. 3A2, 3B2); metanotum slightly to strongly compressed; dark yellow with three black stripes on the scutum or blackish species with pale marks . . . . . 3

3 Blackish species with pale marks; prestigma about as long as wide; clypeus touching the eyes; eyes with hairs; tip of the clypeus sharply pointed (fig. 2A1); metanotum strongly compressed (fig. 2D1); malar space about as long as fourth antennal article (fig. 2B1) . . . P. P. compressa (de Saussure)

3' Dark yellow species with brown to blackish marks; prestigma much longer than wide; clypeus narrowly separated from eyes; eyes bare; tip of the clypeus weakly pointed (fig. 2A2); malar space longer than fourth antennal article (fig. 2B2); metanotum slightly compressed (fig. 2D2)

$P$. vespiceps (de Saussure)

\section{ACKNOWLEDGMENTS}

The authors thank Orlando T. Silveira (MPEG), Augusto Henriques and Marcio Oliveira (INPA), Gabriel Melo and Marcel Hermes (UFPR), Carlos R. Brandão (MZUSP), and Carlos Sarmiento (IIBAVH) for loans of specimens; Kurt M. Pickett and Ward Wheeler for assistance at the AMNH; Sidnei Mateus for assistance in fieldwork; Orlando T. Silveira for sending the photograph of the nest of $P$. langi; and the Fundação de Amparo à Pesquisa do Estado de São Paulo (grants 01/02491-4 and 04/01117-0), Conselho Nacional de Desenvolvimento Científico e Tecnológico (CNPQ), and Collection Study Grant Program (AMNH) for support.

\section{REFERENCES}

Bequaert, J.C. 1938. A new Charterginus from Costa Rica, with notes on Charterginus, Pseudochartergus, Pseudopolybia, Epipona, and Tatua (Hymenoptera, Vespidae). Revista de Entomologia (Rio de Janeiro) 9: 99-117.

Carpenter, J.M. 1991. Phylogenetic relationships and the origin of social behavior in the Vespidae. In K.G. Ross and R.W. Matthew (editors), The social biology of wasps: 7-32. Ithaca, NY: Cornell University Press.

Carpenter, J.M., and S. Mateus. 2004. Males of Nectarinella Bequart (Hymenoptera, Vespidae, Polistinae). Revista Brasileira de Entomologia 48(3): 297-302.

Dejean, A., B. Corbara, and J.M. Carpenter. 1998. Nesting site selection by wasps in the Guianese rain forest. Insectes Sociaux 45: 33-41.

Ducke, A. 1910. Révision des guêpes sociales polygames d'Amérique. Annales HistoricoNaturalis Musei Nationalis Hungarici 8: 449-544.

Goloboff, P.A. 1999a. NONA ver 2.0, program and documentation. Fundación e Instituto Miguel Lillo, Tucumán.

Goloboff, P.A. 1999b. PIWE ver 3.0, program and documentation. Fundación e Instituto Miguel Lillo, Tucumán.

Hanson, P.E., and I.D. Gauld. 1995. The Hymenoptera of Costa Rica. Oxford: Oxford University Press.

Jeanne, R. L 1991. The swarm-founding Polistinae. In K.G. Ross and R.W. Matthew (editors), The social biology of wasps: 191-231. Ithaca, NY: Cornell University Press.

Nixon, K.C. 1999. Winclada, software version 0.9 99i Beta (http://www.cladistics.com). 
Nixon, K.C., and J.M. Carpenter. 1993. On outgroups. Cladistics 9: 413-426.

Richards, O.W. 1978. The social wasps of the Americas excluding the Vespinae. London: British Museum (Natural History).

Richards, O.W., and M.J. Richards. 1951. Observations on the social wasps of South America (Hymenoptera, Vespidae). Transactions of the Royal Entomological Society of London 102: 1-170.

\section{APPENDIX 1}

\section{LOCALITIES FOR SPECIMENS OF PSEUdopolybia STUdied}

P. compressa: Rio Juruá, Ducke Reserve, and Manaus, Amazonas, Brazil (MPEG, AMNH); Espirito Santo (locality not specified), Brazil (MZUSP); Chapada dos Guimarães, Mato Grosso, Brazil (MPEG); Represa Rio Grande, Guanabara [Rio de Janeiro], Brazil (UFPR); Paramaribo, Suriname (IIBAVH); Arima Valley, Trinidad (AMNH); Madre de Dios, Tambopata National Reserve, Peru (AMNH); LaChorarraPutamayo, Peru (AMNH); Napo Province, Ecuador (AMNH); and Changuinola, Bocas del Toro, Panama (AMNH).

P. difficilis: Mato Grosso (locality not specified), Brazil (MPEG); Melgaço, Pará, Brazil (MPEG); Manaus, Amazonas, Brazil (UFPR); Ouro Preto do
Wenzel, J.W. 1998. A generic key to the nests of hornets, yellowjackets, and paper wasps worldwide (Vespidade: Vespinae, Polistinae). American Museum Novitates 3224: 139.

Wenzel, J.W., and J.M. Carpenter. 1994. Comparing methods: adaptative traits and tests of adaptation. In P. Eggleton and R. VaneWright (editors), Phylogenetics and ecology: 79-101. London: Academic Press.

Oeste, Rondônia, Brazil (MPEG); and LaChorerraPutumayo, Peru (AMNH).

P. langi: Laranjal do Jarí Marinho, Amapá, Brazil (MPEG); Manaus, Amazonas, Brazil (UFPR); and Kamakusa, Guyana (AMNH).

P. vespiceps: Espirito Santo state (locality not specified), Brazil (MZUSP); Franca, São Paulo, Brazil (MZUSP); Parque Itaituba, Amazonas, Brazil (MPEG); Amazonas, (AM $01 \mathrm{Km} 31$ and Km 64; ZF $02 \mathrm{Km} \mathrm{20,7;} \mathrm{ZF} 03$ km 23; Amá Station Km 06; Queraí (Pelotão); Ducke Reserve), Brazil (INPA); Rio Trombetas, Amapá, Brazil (INPA); Ouro Preto do Oeste, Rondônia, Brazil; (Garofire, Serra Norte, Mosqueiro and BelémMocambo), Pará, Brazil (MPEG); Pernambuco (locality not specified), Brazil (AMNH); São Paulo (locality not specified), Brazil (male genitalia dissected; AMNH); Oxapampa, Peru (AMNH). 
Complete lists of all issues of the Novitates and the Bulletin are available at World Wide Web site http://library.amnh.org/pubs. Inquire about ordering printed copies via e-mail from scipubs@amnh.org or via standard mail from: American Museum of Natural History, Library-Scientific Publications, Central Park West at 79th St., New York, NY 10024. TEL: (212) 769-5545. FAX: (212) 769-5009.

@ This paper meets the requirements of ANSI/NISO Z39.48-1992 (Permanence of Paper). 